\title{
Structure analysis of FAAP24 reveals single-stranded DNA-binding activity and domain functions in DNA damage response
}

Yucai Wang, ${ }^{2, *}$ Xiao Han ${ }^{1, *}$, Fangming Wu ${ }^{4, *}$, Justin W Leung ${ }^{2}$, Megan G Lowery ${ }^{5}$, Huong Do ${ }^{2}$, Junjie Chen ${ }^{2}$, Chaowei Shi ${ }^{6}$, Changlin Tian ${ }^{4,6}$, Lei Li ${ }^{2,3}$, Weimin Gong ${ }^{1}$

${ }^{1}$ Laboratory of Non-coding RNA, Institute of Biophysics, Chinese Academy of Sciences, Beijing 100101, China; ${ }^{2}$ Department of Experimental Radiation Oncology, The University of Texas MD Anderson Cancer Center, Houston, TX 77030, USA; ${ }^{3}$ Department of Genetics, The University of Texas MD Anderson Cancer Center, Houston, TX 77030, USA; ${ }^{4}$ High Magnetic Field Laboratory, Chinese Academy of Sciences, Hefei, Anhui 230031, China; ${ }^{5}$ Department of Molecular Carcinogenesis, The University of Texas MD Anderson Cancer Center, Smithville, TX 78957, USA; ${ }^{6}$ National Laboratory for Physical Science at Microscale, School of Life Sciences, University of Science and Technology of China, Hefei, Anhui 230026, China

The FANCM/FAAP24 heterodimer has distinct functions in protecting cells from complex DNA lesions such as interstrand crosslinks. These functions rely on the biochemical activity of FANCM/FAAP24 to recognize and bind to damaged DNA or stalled replication forks. However, the DNA-binding activity of this complex was not clearly defined. We investigated how FAAP24 contributes to the DNA-interacting functions of the FANCM/FAAP24 complex by acquiring the N-terminal and C-terminal solution structures of human FAAP24. Modeling of the FAAP24 structure indicates that FAAP24 may possess a high affinity toward single-stranded DNA (ssDNA). Testing of various FAAP24 mutations in vitro and in vivo validated this prediction derived from structural analyses. We found that the DNA-binding and FANCM-interacting functions of FAAP24, although both require the C-terminal $(\mathrm{HhH})_{2}$ domain, can be distinguished by segregation-of-function mutations. These results demonstrate dual roles of FAAP24 in DNA damage response against crosslinking lesions, one through the formation of FANCM/FAAP24 heterodimer and the other via its ssDNA-binding activity required in optimized checkpoint activation.

Keywords: FAAP24; FANCM; DNA binding; DNA damage response

Cell Research (2013) 23:1215-1228. doi:10.1038/cr.2013.124; published online 3 September 2013

\section{Introduction}

Cells have evolved sophisticated mechanisms of DNA damage response and repair to minimize mutations that lead to genomic instability and cancer development. A variety of nucleases are critical DNA repair factors that process damaged DNA. In particular, the XPF family of structure-specific endonucleases is implicated in the re-

*These three authors contributed equally to the work.

Correspondence: Weimin Gong ${ }^{\mathrm{a}}$, Lei $\mathrm{Li}^{\mathrm{b}}$, Changlin Tian ${ }^{\mathrm{c}}$

${ }^{a}$ E-mail: wgong@ibp.ac.cn

bE-mail: 1eili@mdanerson.org

'E-mail: cltian@ustc.edu.cn

Received 26 April 2013; revised 26 July 2013; accepted 7 August 2013; published online 3 September 2013 pair of DNA lesions caused by UV and DNA interstrand crosslinking agents $[1,2]$. Mutation of these genes leads to genomic instability and cancer predisposition. $X P F$ mutations can cause xeroderma pigmentosum, a genetic disease that is highly prone to skin cancer. Fanconi anemia (FA), complementation group $\mathrm{M}$ (FANCM) and FAassociated protein, 24-KD (FAAP24) belong to the XPF family of proteins and are implicated in the repair of UV and interstrand crosslink (ICL) damage $[1,3]$. FANCM mutation has been found in the rare genetic disorder FA [4]. Like xeroderma pigmentosum, FA is a genetically heterogeneous disease. Mutations in any one of the 15 FA genes can cause this disease [5], with manifestation including developmental abnormalities and progressive bone marrow failure that eventually results in pancytopenia. At the cellular level, FA-mutant cells display hyper- 
sensitivity to DNA interstrand crosslinking agents, indicating the importance of the FA pathway in responding to complex DNA damage and strong replication blockage $[6$, 7].

FANCM and FAAP24 function coordinately with other FA and FA-associated proteins to protect cells against ICL damage. They dynamically interact with the FA core complex composed of FA proteins (FANCA, B, $\mathrm{C}, \mathrm{E}, \mathrm{F}, \mathrm{G}$ and $\mathrm{L}$ ) and FA-associated proteins (MHF1, MHF2, FAAP20 and FAAP100) [8-15]. In response to DNA damage, the FA core complex serves as an E3 ligase and monoubiquitinates FANCI and FANCD2 [1618]. Nucleolytic ICL processing is then likely mediated by FAN1 and structure-specific nucleases associated with FANCP/SLX4 [19-24], both of which are thought to be recruited through the binding to ubiquitin. Four other FA/ breast cancer susceptibility proteins, FANCD1/BRCA2, FANCJ/BRIP1, FANCN/PALB2 and FANCO/Rad51C [17, 25-29], function downstream to reestablish replication forks, presumably via homologous recombination.

Previous studies implicated that the DNA-interacting activities of the FANCM/FAAP24 complex are involved in the FA pathway function. FANCM contains a DEAH helicase domain and a degenerated endonuclease domain, and exhibits ATP-dependent DNA translocase activity $[4,9,30]$. FAAP24 is an interacting protein of FANCM. FAAP24 also contains an ERCC4 domain likely possessing DNA-binding activity [9]. Together with the MHF1/ MHF2 histone-fold complex, FANCM/FAAP24 cooperatively bind to and stabilize/remodel stalled replication forks $[15,31,32]$, and target the FA core complex to DNA damage sites to initiate the FA-dependent DNA damage response signaling [33]. FANCM/FAAP24 also carry out additional functions that are important for genomic integrity, including suppression of sister chromatid exchange (SCE) formation [34], recombination-independent ICL repair [34], and ATR-mediated checkpoint activation [34-37].

Biochemically, FANCM and FAAP24 display affinity to various DNA structures with preferences to fork structure and single-stranded DNA (ssDNA), respectively. No detectable binding of FAAP24 to double-stranded DNA (dsDNA) was observed [9, 15]. How FAAP24 exerts these diverse functions and interacts with FANCM in the context of the heterodimer was not well understood. In the present study, we determined the NMR structure of both N-terminal and C-terminal domains of FAAP24 independently. Based on the structural insights, we defined its ssDNA-binding activity and the critical residues of FAAP24 for the FA pathway activation, DNA damage checkpoint function, and cellular survival against ICLs. These data provide insights into how FAAP24 maintains genomic integrity at both structural and molecular levels.

\section{Results}

Solution structures of the ERCC4 and $(\mathrm{HhH})_{2}$ domains of human FAAP24

The solution structures of the N-terminal domain (residues 1-139) and the C-terminal domain (residues 155-215) of human FAAP24 were determined using multi-dimensional NMR. 1713 NOE and 172 dihedral restraints were used to calculate the N-terminal ERCC4like domain of FAAP24. The C-terminal $(\mathrm{HhH})_{2}$ domain of FAAP24 was determined based on 828 NOE restraints and 108 dihedral restraints. An ensemble of 10 conformers with the lowest energy and good convergence was selected out of 100 calculated structures. Statistical data regarding the quality and precision of the ensembles for the two domains are summarized in Supplementary information, Table $\mathrm{S} 1$. The backbone chemical shift assignment $(\mathrm{CO}, \mathrm{C} \alpha, \mathrm{C} \beta$, amide $\mathrm{H}$ and $\mathrm{N})$ of the full-length (FL) protein was also achieved successfully. However, the TALOS+ result indicates that a 22 -residue linker connecting these two domains is exceedingly flexible in solution. The N-terminal tail (residues 1-18) appears unstructured and dynamic in solution.

The structures of the FAAP24 N-terminal and C-terminal domains show a typical ERCC4 nuclease domain comprising a central six-stranded $\beta$-sheet and five flanking $\alpha$ helices on both sides (Figure 1A) and an $(\mathrm{HhH})_{2}$ domain (Figure 1B), respectively. Therefore, FAAP24 appears to be a member of the ERCC1/XPF family. Such conclusion might not be simply predicted via sequence alignment (Supplementary information, Figure S1).

The structure of the ERCC4 nuclease domain of FAAP24 was compared with that of ApeXPF (PDB: 2BHN) and human ERCC1 (PDB: 2JPD and 2A1I) (Figure $1 C$ ). The RMSD values of these structural superimpositions are 2.1, 2.3 and $2.2 \AA$, respectively. There are still some minor differences probably related to the different length of the loops, helices or strands. It was noticed that the $\alpha 4$ helix (residues 96-112) of the FAAP24 ERCC4 nuclease domain was kinked, which might be caused by the presence of a residue Pro (P102) in the primary sequence of this helix. It was reported that the GDXnERKX $_{3} \mathrm{D}$ motif in the ERCC4 nuclease domain of human ERCC1 would be critical for the nucleolytic activity, in which the residue Glu binds to the catalytic metal ion and mutation of the Arg and Lys led to reduced nuclease activity [38]. In FAAP24, the electrically charged residues ERK are substituted by three hydrophobic residues LYV (Supplementary information, Figure S2A). The electrostatic surfaces showed that the key Glu 

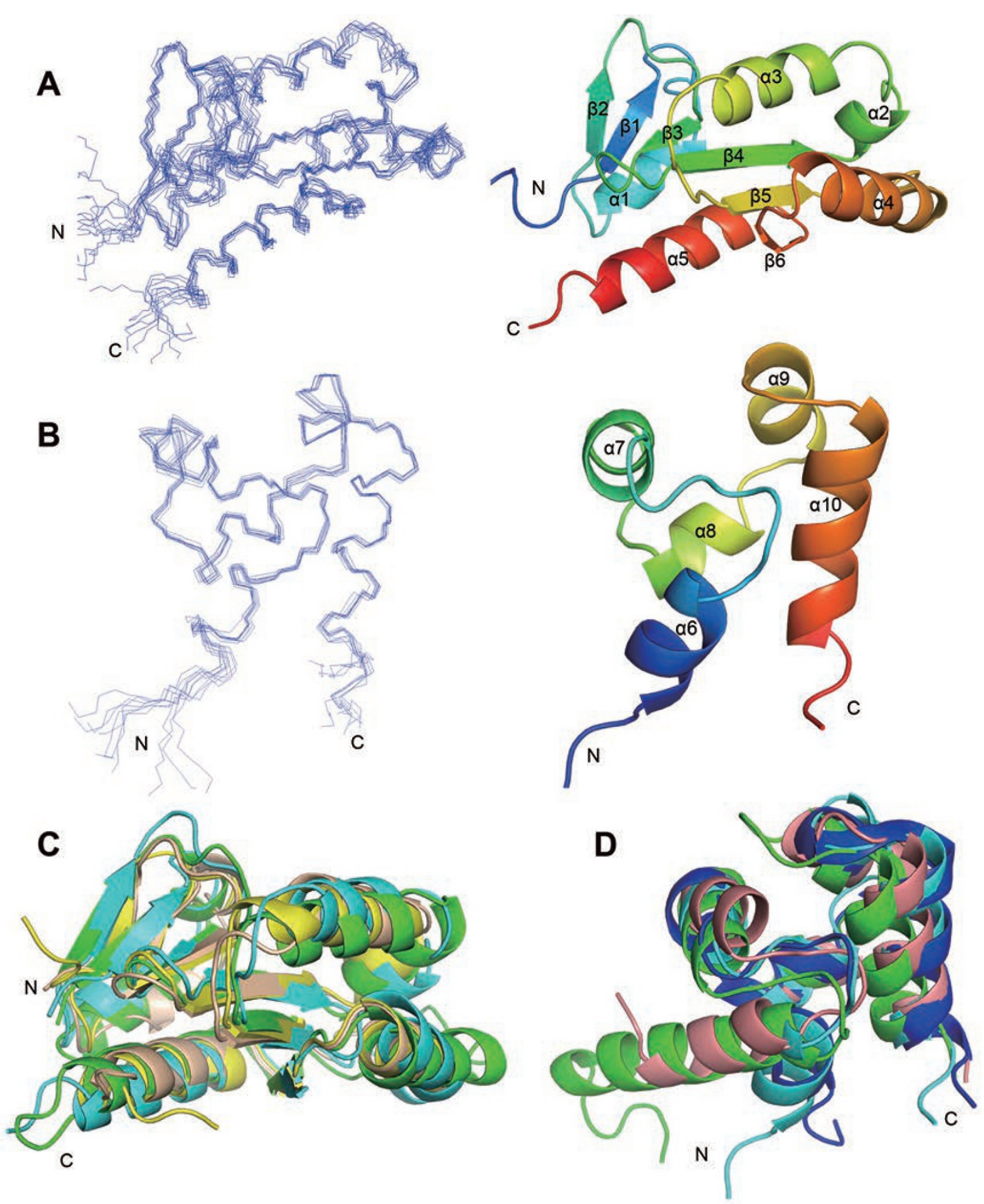

Figure 1 Solution structure of human FAAP24. (A) Solution structure of the N-terminal ERCC4 nuclease domain of FAAP24. Left panel, stereo-view showing the backbones of 10 superimposed NMR-derived structures of the $\mathrm{N}$-terminal domain of FAAP24. Right panel, ribbon diagram of a representative NMR structure of the ERCC4 nuclease domain. The secondary structures of ERCC4 nuclease domain are labeled. (B) Solution structure of the C-terminal $(\mathrm{HhH})_{2}$ domain of FAAP24. Left panel, stereo-view showing the backbones of 10 superimposed NMR-derived structures of the $(\mathrm{HhH})_{2}$ domain of FAAP24. Right panel, ribbon diagram of a representative NMR structure of the $(\mathrm{HhH})_{2}$ domain. The secondary structures of $(\mathrm{HhH})_{2}$ domain are labeled. (C) Structural comparison of four ERCC4 nuclease domains. Cyan: solution structure of the ERCC4 domain of hFAAP24 (PDB: 2M9M); Green, crystal structure of ApeXPF ERCC4 domain (PDB: 2BHN); Wheat, crystal structure of hERCC1 ERCC4 domain (PDB: 2A1I); Yellow, solution structure of hERCC1 ERCC4 domain (PDB: 2JPD). (D) Structural comparison of four $(\mathrm{HhH})_{2}$ domains. Cyan, solution structure of hFAAP24 $(\mathrm{HhH})_{2}$ domain (PDB: 2M9N); Blue, solution structure of hFAAP24 $(\mathrm{HhH})_{2}$ domain (PDB: 2LYH) [39]; Green, solution structure of hERCC1 (HhH) 2 domain (PDB: 1Z00:A); Salmon, solution structure of hXPF $(\mathrm{HhH})_{2}$ domain (PDB: 1Z00:B). 
residues of ApeXPF and pfuXPF are located in a negatively charged cavity, while the same surface of FAAP24 is totally hydrophobic and is surrounded by positive charges (Supplementary information, Figure S2B). In addition, compared with XPF, the helix $\alpha 3$ of FAAP24 covers the active site. This ERK-to-LYV substitution and the orientation of helix $\alpha 3$ most likely degenerate the nuclease activity of FAAP24, consistent with experimental observations that the FANCM-FAAP24 complex has no endonuclease activity $[4,9]$.

The $(\mathrm{HhH})_{2}$ domain of FAAP24 consists of two $\mathrm{HhH}$ motifs bridged by a connecting helix, which forms an integral five-helical domain bearing two $\mathrm{HhH}$ motifs, displaying a pseudo-two-fold symmetry (Figure 1B). The structure of the $(\mathrm{HhH})_{2}$ domain of FAAP24 was compared with the recently reported NMR structure of the hFAAP24 $(\mathrm{HhH})_{2}$ domain (PDB: 2LYH) [39], the solution structures of the $(\mathrm{HhH})_{2}$ domain of hERCC1 (PDB: 1Z00:A) and hXPF (PDB: 1Z00:B) (Figure 1D). The RMSD values of these structural superimpositions are 1.5 , 2.5 and $2.6 \AA$, respectively. It showed that helices $\alpha 7$ $\alpha 10$ were generally well-superimposed between FAAP24 and ERCC1/XFP, while the helix $\alpha 6$ of FAAP2 4 and ERCC1/XPF showed a deflection angle of around 50 degrees (Supplementary information, Figure S2C). This deviation is consistent with the structure of the hFAAP24 $(\mathrm{HhH})_{2}$ domain reported by Wienk et al. [39]. $(\mathrm{HhH})_{2}$ domains are usually found in non-sequence-specific DNAbinding proteins [40]. A consensus GhG motif (h depicts a hydrophobic residue) located in the hairpin is directly involved in protein-DNA interaction. In FAAP24, a G168V169G170 motif is located between helices $\alpha 6$ and $\alpha 7$. This indicates the possibility that the $(\mathrm{HhH})_{2}$ domain of FAAP24 could possess DNA-binding ability.

The $(\mathrm{HhH})_{2}$ domain of FAAP24 is critical for both FANCM association and DNA binding

We next sought to determine which domain(s) of FAAP24 mediate its interaction with FANCM and DNA binding, respectively. To this end, we generated a series of deletion mutants covering the full-length protein (Figure 2A), and determined the FANCM-interacting domain(s) of FAAP24 via co-immunoprecipitation (CoIP) experiments. We co-expressed triple-Myc-tagged full-length FAAP24 or its deletion mutants together with FANCM in HEK293T cells, and immunoprecipitated the protein complex using an anti-Myc antibody. As shown in Figure 2B, the C-terminal deletion mutant D5 completely lost the ability to associate with FANCM, suggesting that the $\mathrm{C}$-terminal $(\mathrm{HhH})_{2}$ motif is important for FANCM interaction.

Tandem HhH motifs are found in many DNA-binding proteins [40] and the $(\mathrm{HhH})_{2}$ domain is therefore a plausible candidate domain that mediates the DNA-binding activity of FAAP24. To test this, we deleted the entire C-terminal $(\mathrm{HhH})_{2}$ domain and tested the in vitro DNAbinding activity of the truncated protein $(\Delta C)$. As the preferred DNA substrate for FAAP24 is ssDNA [9], we tested the full-length FAAP24 protein and the $\triangle \mathrm{C}$ mutant for their binding of a 20-nt ssDNA in vitro using SPR assays. As shown in Figure 2C, the deletion of the $(\mathrm{HhH})_{2}$ domain completely abolished the robust ssDNA-binding activity of FAAP24 as observed with the full-length protein, suggesting that the $\mathrm{C}$-terminal $(\mathrm{HhH})_{2}$ motif is also responsible for ssDNA binding.

\section{Identification of residues important for FAAP24 binding to ssDNA}

The nucleic acid-binding properties of FAAP24 were further characterized by NMR titration with 12-nt and 20-nt ssDNA (Figure 3A). We found that the overall fold of FAAP24 remains unaltered, which suggested that the observed chemical shift perturbations arose from specific contacts with ssDNA. Critical residues for DNA binding were identified using the backbone assignments for FAAP24. A comparison of the ${ }^{15} \mathrm{~N}$ HSQC spectra for FAAP24 in the presence and absence of DNA revealed that the following residues were markedly perturbed when FAAP24 interacts with either 12-nt or 20-nt ssDNA: G168, G170, K171 and K173 (the amide signal of K173 disappeared upon titration of ssDNA). Chemical shift perturbation data analysis showed that these most prominent changes in chemical shifts involved a cluster of residues within the first $\mathrm{HhH}$ motif of the FAAP24 $(\mathrm{HhH})_{2}$ domain, especially the strictly conserved GVG motif (G168, G170) and two ensuing residues (K171, K173).

To further verify whether the above-identified residues are indeed important for DNA binding, we performed the SPR assay on several single amino-acid substitution mutants. As shown in Figure 3B, the G168A mutation significantly reduced ssDNA-binding affinity of the FAAP24 protein, suggesting that the GVG motif is critical for DNA binding. However, the G170A mutation rendered recombinant FAAP24 protein insoluble, suggesting that a major structural disruption occurred with such substitution.

To verify that K171 and K173 are important for DNA binding, we generated K171A, K173 A and K171A/ K173A substitution mutants of FAAP24. As shown in Figure $3 \mathrm{C}$, alanine substitution of the lysine residues resulted in a dramatic decrease of the in vitro DNA-binding activity. Quantitatively (Supplementary information, Figure S3A), the binding affinity of wild-type FAAP24 


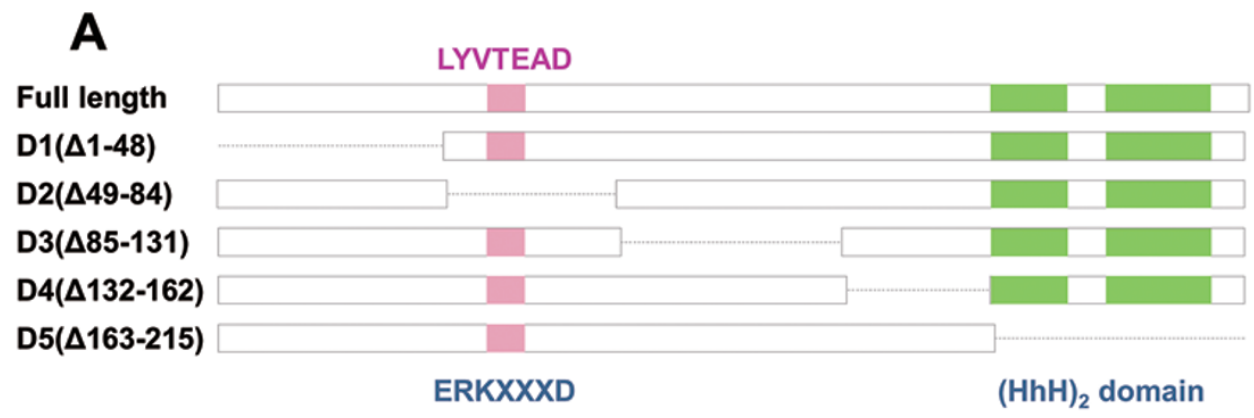

B
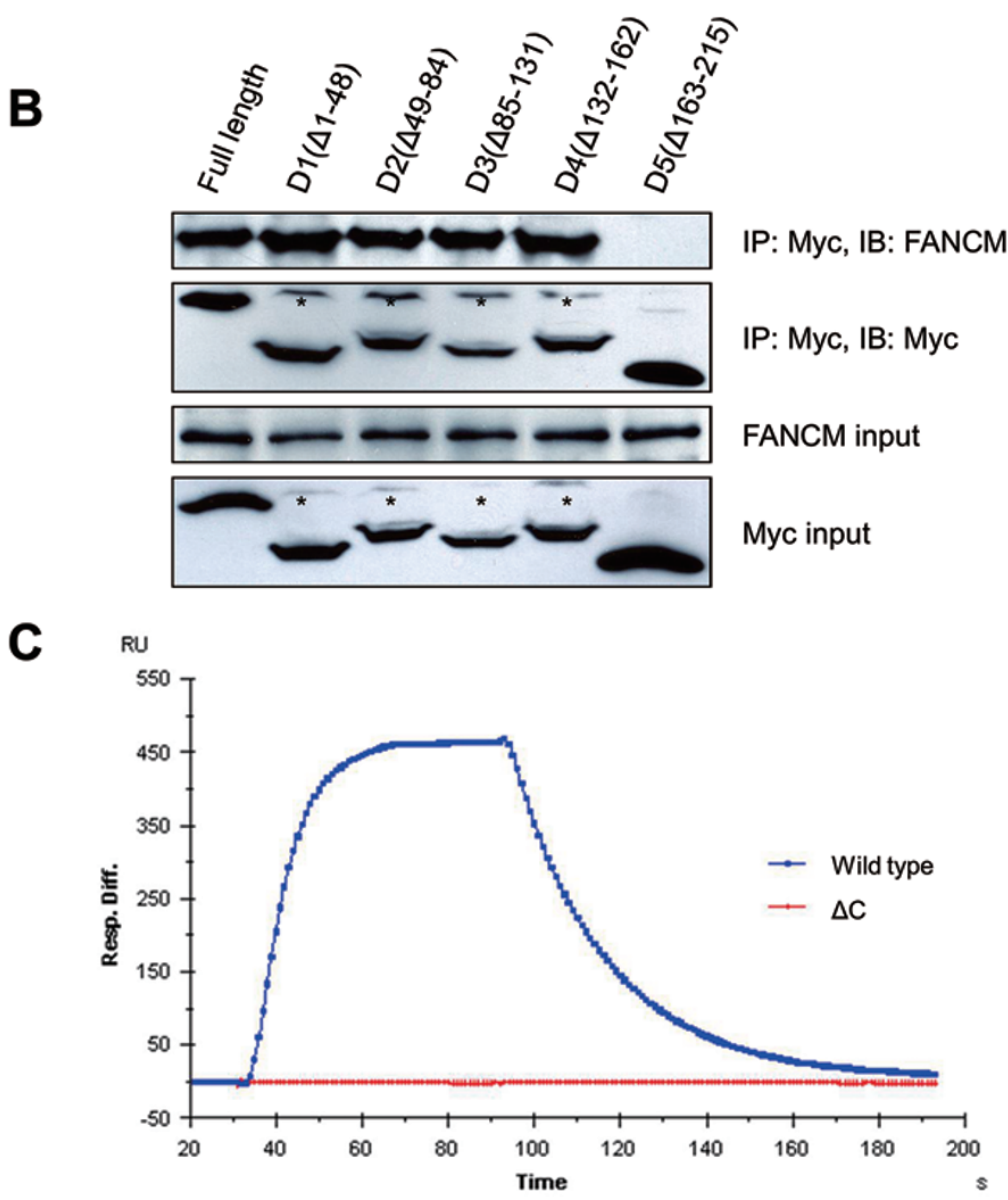

Figure 2 The $(\mathrm{HhH})_{2}$ domain of FAAP24 is required for FANCM interaction and DNA binding. (A) Schematics of FAAP24 truncation mutants used for Co-IP experiment in B. Pink-shaded areas depict the degenerated nuclease motif. Green-shaded areas depict the tandem $\mathrm{HhH}$ repeat. (B) Co-IP of Myc-tagged wild-type FAAP24 or the truncation mutants with FANCM. HEK293T cells were co-transfected with plasmids encoding Myc-tagged FAAP24 and FANCM, and the cell lysates were subjected to immunoprecipitation with an Myc antibody. Asterisks indicate nonspecific bands associated with anti-Myc antibody. (C) SPR assay measuring ssDNA-binding affinity of wild-type FAAP24 and the C-terminal $(\mathrm{HhH})_{2}$ domain truncation mutant $(\triangle \mathrm{C})$.

to ssDNA is high with a dissociation constant $(K d)$ of 3.69E-07M. When mutations were introduced at these positive residues (K171A, K173A and K171A/K173A), the binding affinity reduced to $3.14 \mathrm{E}-06 \mathrm{M}, 2.43 \mathrm{E}-06 \mathrm{M}$ and $5.10 \mathrm{E}-06 \mathrm{M}$, respectively (up to 13 -fold reduction). Substitution of the lysine residues with glutamic acid also greatly compromised the DNA-binding activity of FAAP24 (Supplementary information, Figure S3B).

Identification of residues important for in vivo chromatin association

Next we sought to systemically determine which resi- 
A
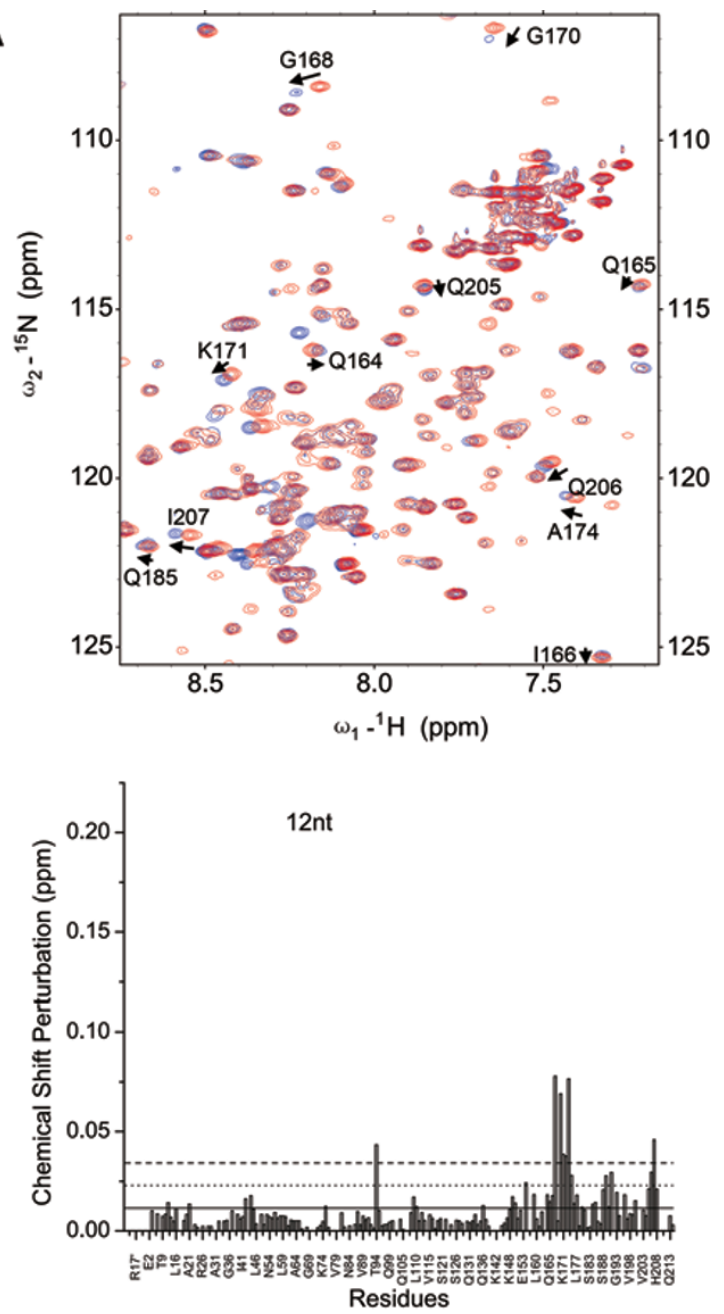

B

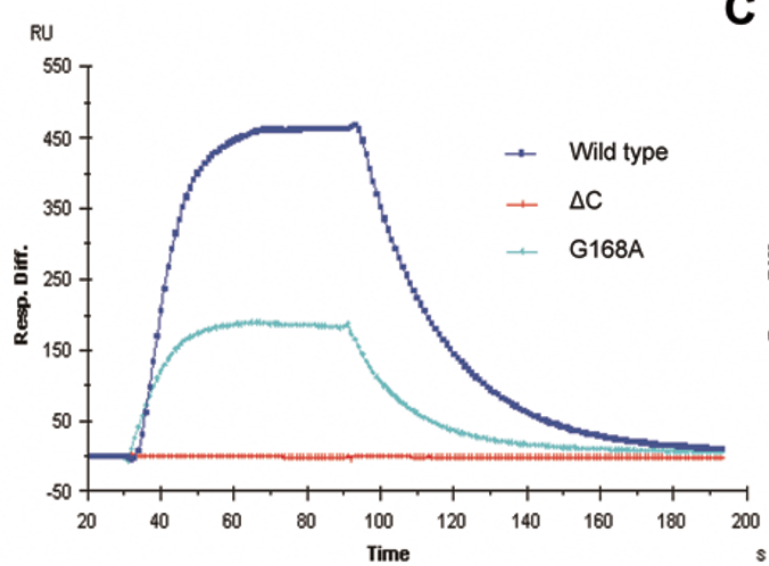

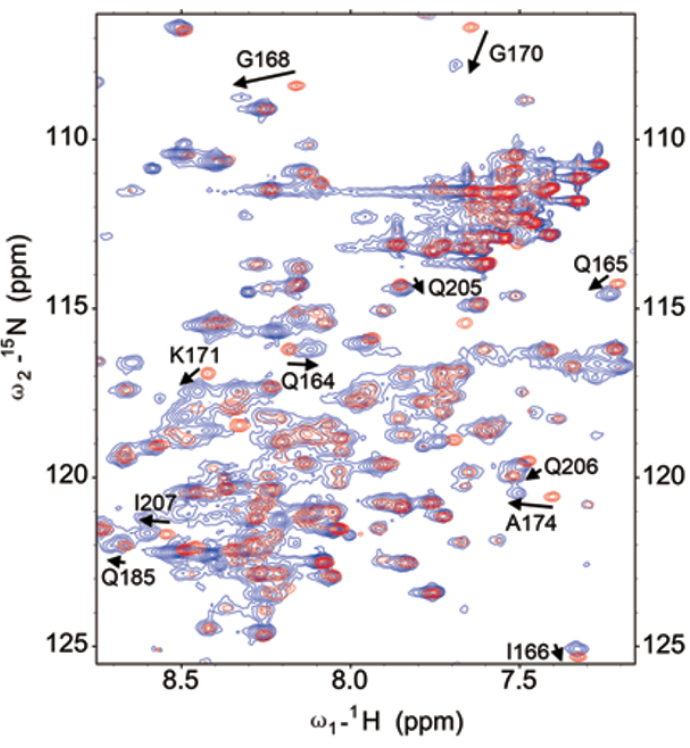

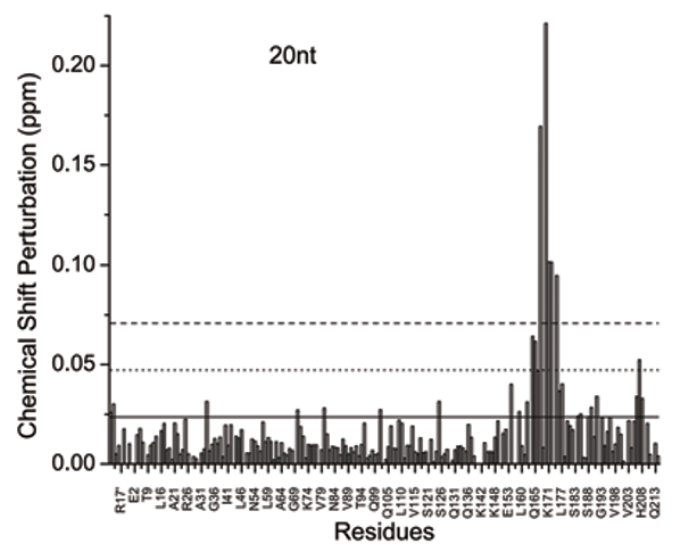

C

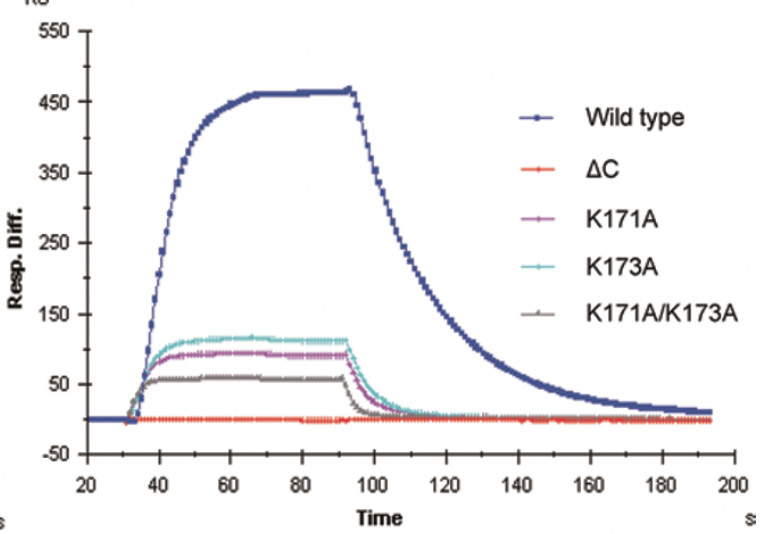

Figure 3 Identification of critical residues of FAAP24 for ssDNA binding. (A) NMR titration experiments of FL-FAAP24 with 12-nt (upper left) and 20-nt (upper right) ssDNA. Five HSQC spectra were recorded with ssDNA:FL-FAAP24 ratio at 0:1, $0.3: 1,0.5: 1,1: 1$, and 2:1, respectively. For better illustration, only the first (red, ssDNA:FL-FAAP24 = $0: 1)$ and the last (blue, ssDNA:FL-FAAP24 = 2:1) spectra were shown and overlapped. Peaks that were obviously shifted were labeled by arrows. In each panel, solid, dotted and dashed horizontal lines correspond to the averaged CSP, one and two standard deviations above the averaged CSP, respectively (see Materials and Methods for details). (B) SPR assay measuring ssDNA-binding affinity of the $\mathrm{G} 168 \mathrm{~A}$ mutant and the $\mathrm{C}$-terminal $(\mathrm{HhH})_{2}$ domain truncation mutant $(\triangle \mathrm{C})$. (C) SPR assay measuring ssDNAbinding affinity of K171A, K173A and K171A/K173A mutants. 
dues are important for FAAP24 DNA binding in vivo. To this end, we generated a series of FAAP24 mutants with amino acid substitutions of conserved and NMR structure-implicated residues (Supplementary information, Figure S4). These mutations cover the core ERKxxxD motif in the ERCC4 domain and key residues in the $(\mathrm{HhH})_{2}$ domain. We stably expressed triple-Myc-tagged FAAP24 mutants in a FAAP $24^{-/-}$somatic knockout cell line we previously generated [34], and tested the chromatin association of these mutants in the stable cell lines. As controls, we also generated in-parallel stable cell lines expressing wild-type FAAP24 and the D5 mutant. As shown in Figure 4, wild-type FAAP24 associates with chromatin with high affinity. In contrast, FAAP24 D5 mutant, which lacks the $(\mathrm{HhH})_{2}$ domain, was completely deficient in chromatin association. This result further demonstrates that the $(\mathrm{HhH})_{2}$ domain is indispensable for FAAP24 to bind DNA. Importantly, the V169A, K173A and $\mathrm{K} 171 \mathrm{~A} / \mathrm{K} 173 \mathrm{~A}$ mutants showed significantly reduced affinity with chromatin, again indicating that the GVGKVK motif is important for DNA interaction. In addition, L177A, LLL176-178AAA, L187A and F201A/ F211A mutants also displayed unfavorable chromatin
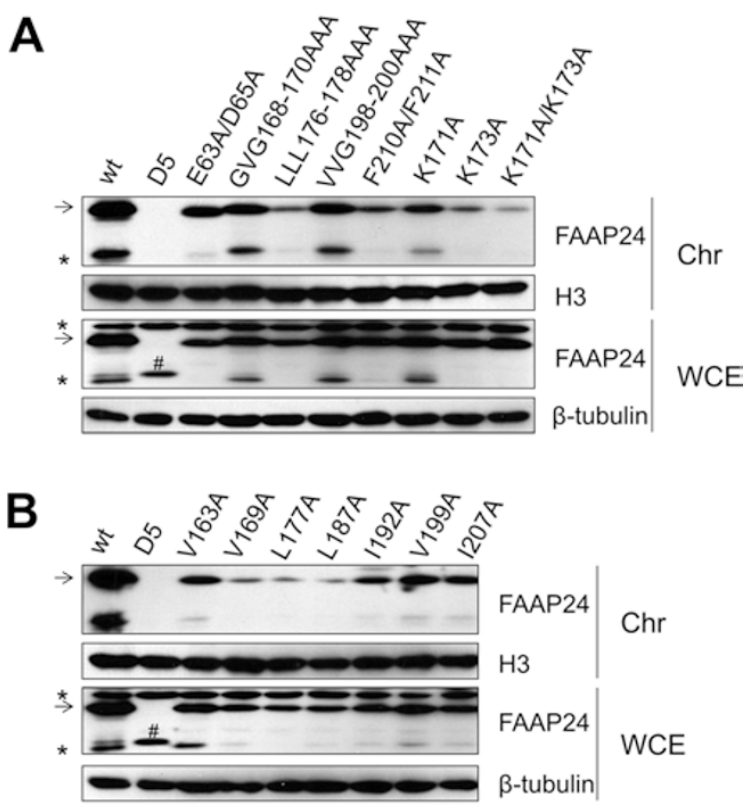

Figure 4 Chromatin association of wild-type and mutant FAAP24. (A-B) FAAP $24^{-1-}$ cells stably complemented with Myc-tagged wild-type or mutant FAAP24 were fractionated, and western blot analysis was performed to detect FAAP24. Chr: chromatin fraction; WCE: whole-cell extract. Arrows indicate Myc-tagged FAAP24 proteins. The \# marks Myc-tagged D5 mutant. Asterisks indicate either nonspecific bands associated with the antiMyc antibody or potential degradation bands. association activity, suggesting that these hydrophobic residues are also important for DNA binding.

Consistently, SPR assay on selected mutants also confirmed that V169, LLL176-178, L187 and FF210-211 are important for in vitro DNA binding of FAAP24 (Supplementary information, Figure S5), further validating the importance of these residues in the DNA-binding affinity of FAAP24.

Identification of residues important for FANCM interaction

Our results from the in vitro DNA-binding assay and in vivo chromatin-association experiments are largely consistent with each other, suggesting that chromatin binding of FAAP24 is likely reflective of its intrinsic DNA-binding activity. As both FANCM and the FANCM/FAAP24 complex display in vitro DNAbinding activities, it is important to determine whether FANCM interaction impacts the DNA-binding activity of FAAP24. We tested FAAP24 mutants described above for FANCM interaction. We co-expressed triple-Myc-tagged FAAP24 mutants together with FANCM in HEK293T cells and tested FANCM-FAAP24 interaction by Co-IP experiments. As shown in Supplementary information, Figure S6, single amino-acid substitution within the $(\mathrm{HhH})_{2}$ domain did not disrupt FAAP24 interaction with FANCM, suggesting that the protein-interacting surface may involve multiple residues of FAAP24. When two to three amino acids were substituted, which likely caused a more severe disruption of the interacting interface, most mutants, including GVG168-170AAA, LLL176178AAA, VVG198-200AAA and F201A/F211A, lost the ability to associate with FANCM. We also examined the FAAP24 mutants for FANCM interaction in endogenous settings by using lysates from $F A A P 24^{-/-}$cells expressing various FAAP24 mutants for Co-IP experiments. The results (Figure 5) were consistent with those from CoIP experiments of exogenous proteins. Notably, although two mutants (LLL176-178AAA and F201A/F211A) displayed both decreased DNA binding/chromatin association and abolished FANCM interaction, most point mutants are only defective for one of these two activities, suggesting that FANCM interaction and chromatin association are not interdependent.

Both FANCM-interacting and DNA-binding activities are important for FAAP24 function in the FA pathway

A systematic examination of FAAP24 mutants for FANCM interaction and DNA binding led to the identification of mutants defective for one or both of these functions, which suggests a possible segregation of the FANCM-association and DNA-binding functions of 

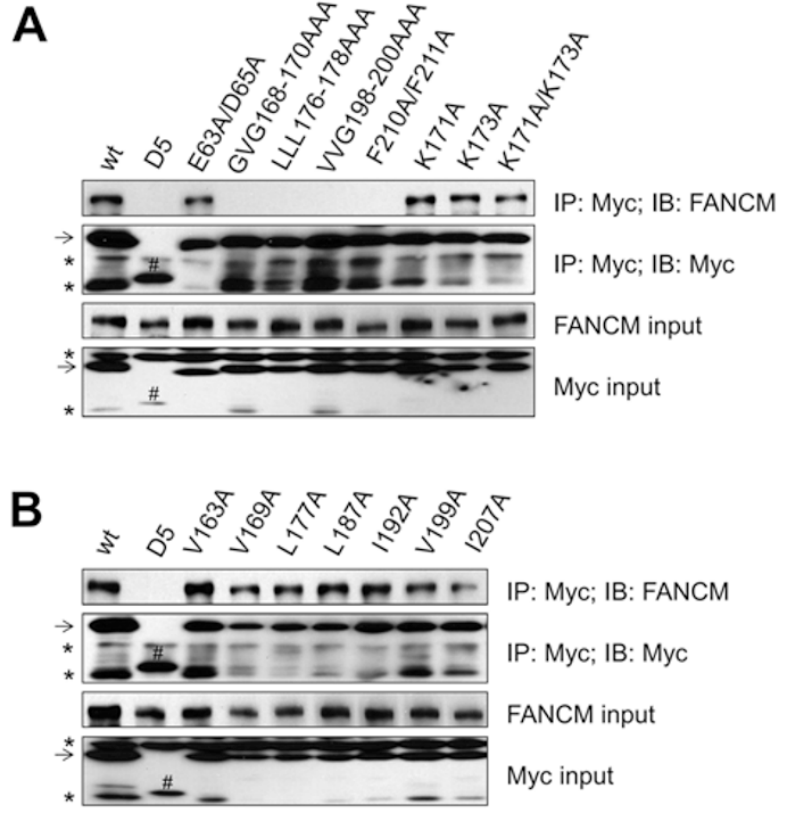

Figure 5 Co-IP of Myc-tagged wild-type or mutant FAAP24 with FANCM. (A-B) Lysates of FAAP $24^{-1-}$ cells stably complemented with Myc-tagged wild-type or mutant FAAP24 were subjected to immunoprecipitation with an Myc antibody, and western blot analysis was performed to detect FANCM and FAAP24. Arrows indicate Myc-tagged FAAP24 proteins. The \# marks Myc-tagged D5 mutant. Asterisks indicate either nonspecific bands associated with the anti-Myc antibody or potential degradation bands.

FAAP24, and allows a fine dissection of their importance in the FA pathway activation and other DNA damage response events.

We first treated the stable cells carrying various FAAP24 mutants (Supplementary information, Table S2) with mitomycin C (MMC) and examined FANCD2 monoubiquitination, a marker for the FA pathway activation. As shown in Figure 6A, FAAP $24^{-/-}$cells displayed significant defect of FA pathway activation compared with parental wild-type HCT-116 cells. This defect can be fully rescued by complementation with full-length FAAP24 protein but not the D5 mutant, suggesting that the $(\mathrm{HhH})_{2}$ domain is indispensable for FAAP24 function in the FA pathway. An ERCC4 domain mutant E63A/D65A was also competent in complementing the FANCD2 monoubiquitination deficiency of FAAP $24^{-/}$ cells, suggesting that the diverged ERCC4 domain of FAAP24 is less important for the FA pathway activation. Among the $(\mathrm{HhH})_{2}$ domain mutants, those defective for FANCM interaction (GVG168-170AAA and VVG198200AAA) or DNA binding (K171A, K173A, K171A/ K173A, V169A, L177A and L187A) only partially restored FANCD2 monoubiquitination, while mutants de- fective for both (LLL176-178AAA and F201A/F211A) showed little rescue of FANCD2 monoubiquitination, suggesting that both FANCM-interacting and DNAbinding activities of FAAP24 are important for the FA pathway activation.

We also tested FANCD2 foci formation in response to MMC damage in FAAP $24^{-/-}$cells stably expressing FAAP24 mutants. As shown in Figure 6B and Supplementary information, Figure S7, the results were consistent with FANCD2 monoubiquitination data and further support that both FANCM-interaction and DNA-binding functions of FAAP24 are required for FA pathway activation.

DNA-binding activity of FAAP24 is critical for ATRdependent checkpoint activation in response to ICL damage

We recently reported that FAAP24 but not FANCM is required for optimal activation of ATR-dependent checkpoint in response to ICL damage. We sought to determine whether FANCM interaction and/or DNAbinding activity of FAAP24 are important for its role in DNA damage checkpoint activation. FAAP $24^{-1-}$ cells stably complemented with various FAAP24 mutants were exposed to MMC and examined for their ATR-mediated checkpoint activation by blotting for Chk1 phosphorylation at Ser317. As shown in Figure 7A, FAAP24 $4^{-1-}$ cells displayed readily detectable checkpoint activation defect, which could be complemented by wild-type FAAP24 proteins. Mutants that are only defective for FANCM binding were able to fully rescue Chk1 phosphorylation. In contrast, mutants deficient in DNA binding were incompetent in restoring Chk1 activation, indicating that DNA-binding activity of FAAP24 is required for optimal activation of ATR-mediated checkpoint activation.

To functionally extend the above results, we tested the sensitivity of mutant-complemented FAAP $24^{-/-}$cells to MMC. As shown in Figure 7B, the ERCC4 domain mutant E63A/D65A fully rescued the MMC-hypersensitive phenotype of $F A A P 24^{-1}$ cells, indicating that this domain is dispensable for crosslinking damage resistance. In contrast, the D5 mutant-complemented cells displayed low survival comparable to the $F A A P 24^{-/-}$cells, again suggesting that the $(\mathrm{HhH})_{2}$ domain is critical for FAAP24 function. Mutants defective for FANCM interaction or DNA binding only partially corrected the MMC-hypersensitive phenotype of FAAP $24^{-/-}$cells, while mutants defective for both showed little correction, pointing to a dual requirement of FANCM association and DNA-binding affinity for FAAP24 to function in cellular resistance to ICL damage. 
A
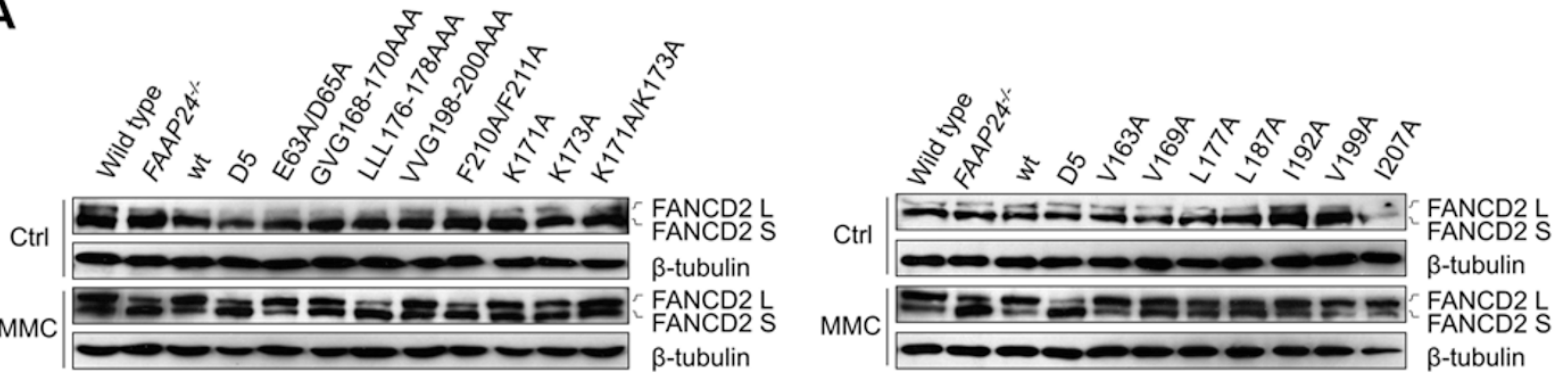

B

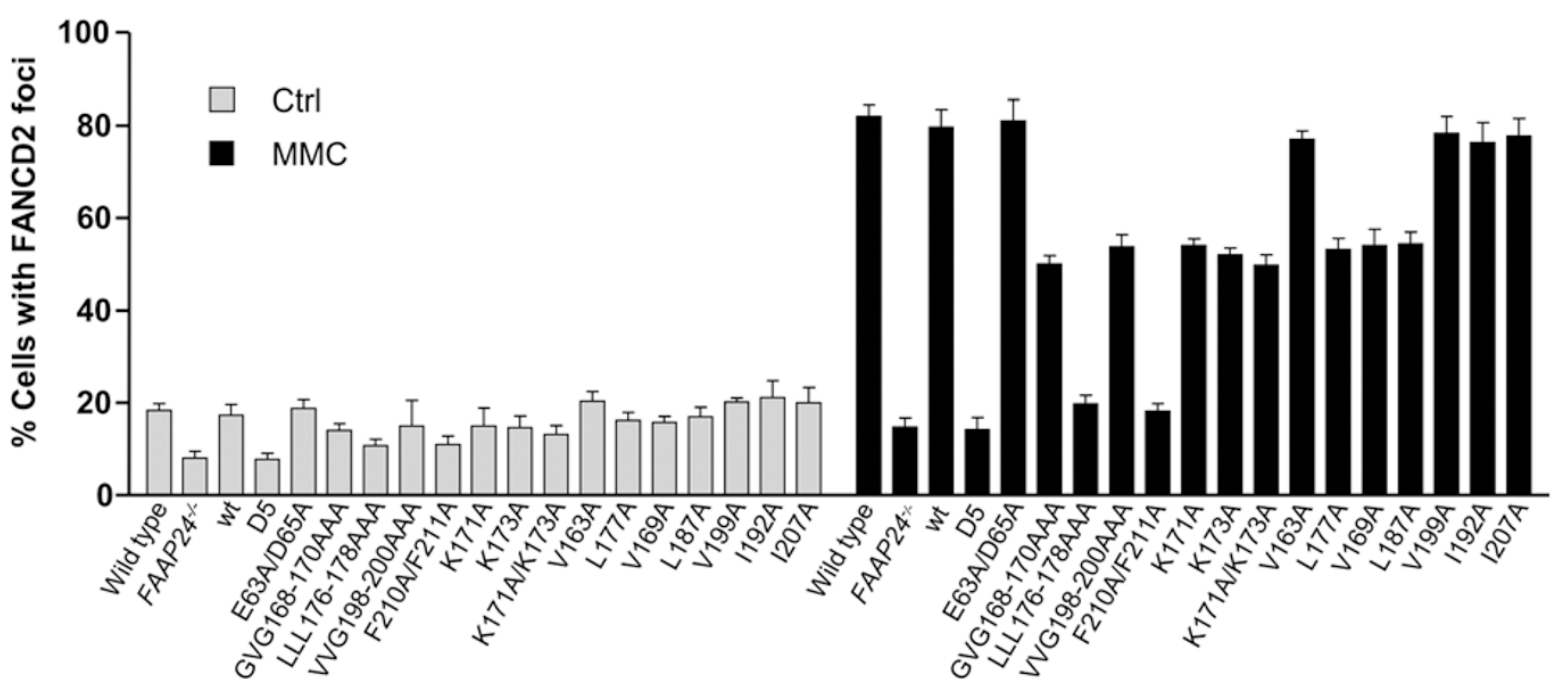

Figure 6 Both FANCM-interacting and DNA-binding activities of FAAP24 are required for the FA pathway activation. (A) FANCD2 monoubiquitination in FAAP24 $4^{-1-}$ cells stably complemented with wild-type or mutant FAAP24. Cells were mocktreated (Ctrl) or treated with $200 \mathrm{ng} / \mathrm{ml}$ MMC for $16 \mathrm{~h}$. L and S represent monoubiquitinated and native forms of FANCD2, respectively. (B) Quantification of FANCD2 foci formation in FAAP24 ${ }^{-1-}$ cells stably complemented with wild-type or mutant FAAP24. Cells were mock-treated (Ctrl) or treated with $500 \mathrm{ng} / \mathrm{ml} \mathrm{MMC}$ for $24 \mathrm{~h}$. Data represent three independent experiments and error bars depict SD derived from five data sets.

\section{Discussion}

The DNA remodeling enzyme FANCM and its binding partner FAAP24 have been implicated in a number of DNA damage response and repair processes, including the FA pathway activation, ATR-dependent DNA damage checkpoint signaling, and recombination-independent repair of ICLs. These intercalated functions may either depend on the FANCM/FAAP24 complex function or rely on intrinsic biochemical activities of FANCM or FAAP24 alone. For example, FAAP24 functions cooperatively with FANCM to activate the FA pathway and suppress SCE formation, but it also independently promotes optimal ATR-mediated checkpoint activation in response to ICL damage [34]. To further understand how FAAP24 executes distinct functions to maintain genomic stability, we undertook structural and molecular approaches to dissect how FAAP24 interacts with FANCM and DNA, and how these activities contribute to FAAP24 functions in different settings.

FANCM/FAAP24 exhibit domains reminiscent of those of the XPF/ERCC1 and MUS81/EME1 structurespecific endonuclease complexes. However, neither FANCM nor FAAP24 has been found to possess nuclease activity. We found that folding of the ERCC4 domain of FAAP24 is in line with typical ERCC4 nuclease domains, and the overall structure highly resembles those of ApeXPF and human ERCC1 (Figure 1C). The critical core motif of a catalytic ERCC4 domain consists of ERKxxxD. In ApeXPF, the ERK residues are located in a central $\beta$-strand, while the following TSSD residues are part of a following helix structure [1]. In human 
A
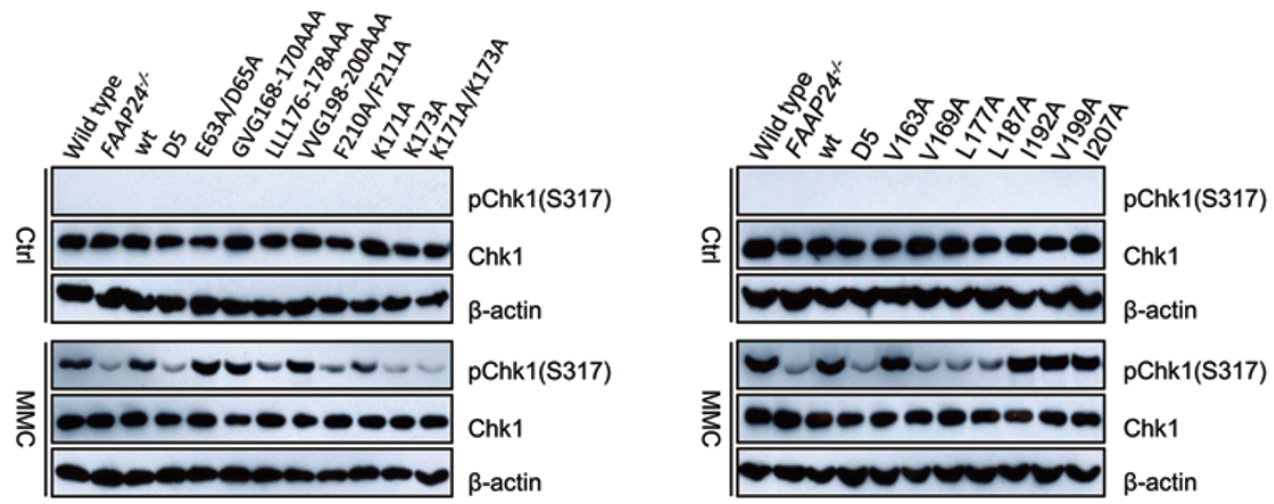

B

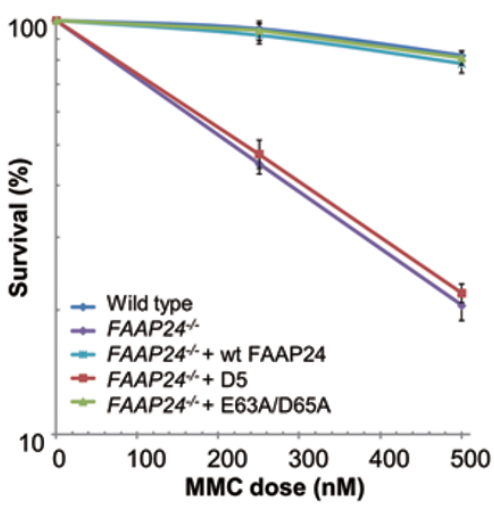

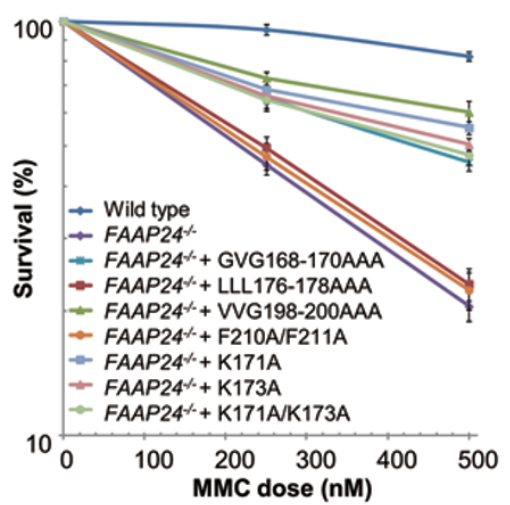

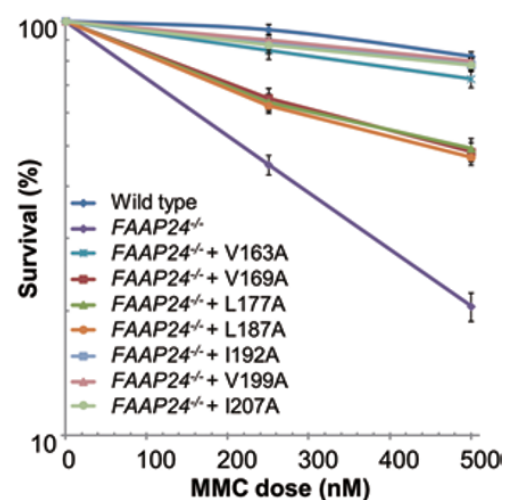

Figure 7 DNA-binding activity of FAAP24 is required for ATR-mediated checkpoint activation in response to ICL damage. (A) Ser317 phosphorylation of Chk1 in FAAP24 $4^{-1-}$ cells stably complemented with wild-type or mutant FAAP24. Cells were mocktreated (Ctrl) or treated with $150 \mathrm{ng} / \mathrm{ml} \mathrm{MMC}$ for $6 \mathrm{~h}$. Chk1 and $\beta$-actin serve as loading controls. (B) Clonogenic survival of FAAP $24^{-/-}$cells stably complemented with wild-type or mutant FAAP24. Error bars represent SD from four independent experiments with triplicated plates.

FAAP24, the diverged ERKxxxD motif is folded in a similar manner: the LYV and TEAD residues are within a $\beta$-strand and a following helix, respectively. Thus, the loss of nuclease activity in FAAP24 does not seem to be attributed to severe local structural folding disruption. Rather, a change of amino-acid properties due to ERK-to-LYV degeneration is detrimental. Substitution of these residues likely interferes with an otherwise functional nuclease active site. Although an E63A/D65A mutant in our study appears to function as well as wildtype FAAP24, it remains unclear whether the diverged ERKxxxD motif in FAAP24 confers other functions.

Previously, the ERCC4 domain of ERCC1 was shown to bind ssDNA in the absence of its $(\mathrm{HhH})_{2}$ domain [41]. NMR titration experiments indicated that N99, I102, L132, K213, A214 and the side-chain amide of Q134 contribute to such ssDNA-binding ability. Among them, the only positively charged residue K213 is fully conserved in the ERCC1 family of proteins. However, structural superimposition (Figure 1D) and sequence align- ment (Supplementary information, Figure S1) between ERCC4 domains of ERCC1 and FAAP24 showed that the conserved Lys residue is replaced by a hydrophobic residue (V133) in FAAP24. This substitution most likely disrupts the ssDNA affinity of the FAAP24 ERCC4 domain.

On the other hand, $(\mathrm{HhH})_{2}$ motifs are found in many DNA-binding proteins and are thought to be important for interacting with DNA. In the recently published work the $(\mathrm{HhH})_{2}$ domain of FAAP24 was suggested to bind dsDNA when a FAAP24 truncate (residues 139-215) was used in the NMR titrations [39]. We believe that the truncated FAAP24 used in this study might have lost certain constrains from the ERCC4 domain, allowing the $(\mathrm{HhH})_{2}$ domain to bind both ssDNA and dsDNA. This may underline the discrepancy between what was observed by Wienk et al. [39] and our studies using the full-length FAAP24. Using both NMR titration and SPR assays, we found that the $(\mathrm{HhH})_{2}$ domain of FAAP24 is essential for its ssDNA-binding activity (Figure $3 \mathrm{~A}$ and $3 \mathrm{~B}$ ). The hair- 
pins in a $(\mathrm{HhH})_{2}$ domain are important for DNA binding. In particular, the classical glycine-hydrophobic residueglycine $(\mathrm{GhG})$ hairpins are critical for DNA interactions. In ApeXPF, two GIG hairpins are present and they cooperatively bind the backbone phosphates from two strands of a duplex DNA. Several positively charged residues immediately following the GIG hairpins also contribute to the interaction with the minor groove [42]. In contrast, FAAP24 contains only one classical GVG hairpin in the first $\mathrm{HhH}$ motif, which is immediately followed by positively charged K171 and K173. In the second HhH motif, there is no GhG hairpin and no alkaline residues following the VVG residues. As a result, the $(\mathrm{HhH})_{2}$ domain of FAAP24 might only make contact with one strand of a duplex DNA. This may dictate that FAAP24 prefers ssDNA (Supplementary information, Figure S8A). In addition to the GVGKVK residues, we found that several hydrophobic residues within the $(\mathrm{HhH})_{2}$ domain also contribute to ssDNA-binding affinity of FAAP24. Most likely, these residues are important for a stable $(\mathrm{HhH})_{2}$ structure that allows a favorable DNA interaction. For example, the F210 and F211 residues reside in the tail of the last helix, and together with L158 and I166 on the first helix, they form a hydrophobic core that might be crucial for maintaining the overall $(\mathrm{HhH})_{2}$ structure by controlling its opening (Supplementary information, Figure $\mathrm{S} 8 \mathrm{~B}$ ).

FANCM contains an ERCC4 domain and an $(\mathrm{HhH})_{2}$ domain in its $\mathrm{C}$-terminus. However, the $\mathrm{C}$-terminus of FANCM ( FANCM $\left._{1727-2048}\right)$ by itself does not exhibit DNA-binding activities [9]. This is probably because that FANCM does not contain classical GhG hairpins in the $(\mathrm{HhH})_{2}$ domain. The $\mathrm{FANCM}_{1727-2048} / \mathrm{FAAP} 24$ dimer could bind a variety of substrates with a preference for splayed-arm DNA, suggesting that FAAP24 is important for targeting FANCM to DNA $[9,33]$. This resembles the DNA-binding property of XPF/ERCC1. ERCC1 contains one classical GhG hairpin while XPF contains none, and it has been shown that ERCC1 binds ssDNA and is important for targeting XPF to DNA $[9,43]$.

FANCM also contains a helicase domain, which confers a DNA translocase activity. Although FANCM $_{1727-2048}$ does not have DNA-binding activity, full-length FANCM can bind forked DNA structures [15]. Therefore, FANCM/FAAP24 complex may bind DNA through two independent surfaces, the $(\mathrm{HhH})_{2}$ domain of FAAP2 4 and the helicase domain of FANCM. This allows the complex to bind replication fork structures synergistically. In fact, it has been proposed that FANCM/FAAP24 and MHF1/2 complexes cooperatively bind stalled replication fork such that FANCM binds to the branch while MHF1/2 and FAAP24 associate with dsDNA and ssDNA regions, respectively [15]. This cooperative binding model may underscore why both FANCM-interaction and DNAbinding activities of FAAP2 4 are required for optimal FA pathway activation in response to ICL damage that stalls replication forks (Figure 6 and Supplementary information, Figure S7).

We showed previously that the function of FAAP24 in FA pathway activation can be segregated from its function in DNA damage checkpoint signaling - the former is attained cooperatively with FANCM while the latter is independent of FANCM. Here we show that disrupting either FANCM interaction or DNA binding of FAAP24 compromised the activation of FA pathway, suggesting that both activities are important. A cooperative and more stable binding of stalled forks by the FANCM/FAAP24 complex may be required for an efficient recruitment of the FA core complex to the damage sites. On the other hand, we found that only the DNA-binding activity of FAAP24 was important for ATR-dependent checkpoint activation in response to ICL damage. This is consistent with the finding that FANCM seems dispensable for this process. FAAP24 was shown to have affinity toward ICL DNA structures, which is a plausible explanation of its role in ICL-induced checkpoint activation. Our results clearly demonstrated that DNA binding-defective FAAP24 mutants do not support robust ATR-dependent checkpoint activation by ICL damage, suggesting that the role of FAAP24 in this process strictly depends on its ssDNA-binding activity. It is possible that the ICL DNAbinding and the ssDNA-binding activities of FAAP24 are important for enhancing ATR/ATRIP recruitment in the context of ICL damage.

Future investigations, especially with crystal structures of FAAP24, co-crystal structures of FANCM C-terminus/ FAAP24, with and without DNA, will be invaluable in understanding how these proteins interact with each other and how they associate with DNA. Structure of fulllength FANCM/FAAP24 and structure-function analysis using genetic platforms will provide additional important insights into the functions of these proteins.

\section{Materials and Methods}

\section{Cloning, protein expression and purification}

The full-length human FAAP24 gene was PCR-amplified from pDONR201 and subcloned into the pET28a (Novagen) bacterial expression vector between $N d e \mathrm{I}$ and $\mathrm{XhoI}$ sites. FAAP24 Nterminal domain (residues 1 to 139) was subcloned into the pET22b (Novagen) between NdeI and XhoI sites, C-terminal domain (residues 158-215) was subcloned into the pET-28a-sumo (Novagen) between BamHI and XhoI sites. Point mutations of FAAP24 were created using the standard PCR-based mutagenesis method. As a result all the constructs contained an N-terminal his-tag. The 
nucleotide sequences of the cloned DNAs were confirmed by DNA sequencing (Sangon). Recombinant proteins were expressed in Escherichia coli Rosetta host cells. Cells were grown at $37^{\circ} \mathrm{C}$ to an $\mathrm{OD}_{600}=0.8$ and induced with $0.5 \mathrm{mM}$ IPTG at $16{ }^{\circ} \mathrm{C}$ for $16 \mathrm{~h}$. The target proteins were purified by $\mathrm{Ni}^{2+}$-IDA agarose affinity chromatography and further purified by two steps of column chromatography with HiTrap SPFF $5 \mathrm{ml}$ and Superdex $75120 \mathrm{ml}$ columns (GE Healthcare).

Uniformly isotope-labeled FAAP24 was prepared by growing bacteria in M9 minimal medium using ${ }^{15} \mathrm{NH}_{4} \mathrm{Cl}$ as the sole nitrogen source or ${ }^{15} \mathrm{NH}_{4} \mathrm{Cl}$ and ${ }^{13} \mathrm{C}_{6}$-glucose as the sole nitrogen and carbon sources, respectively. The NMR samples were concentrated to $0.3 \mathrm{mM}$ (for titration experiments) or $0.5 \mathrm{mM}$ (for structural determination) in $50 \mathrm{mM}$ potassium phosphate $\mathrm{pH} 6.0,50 \mathrm{mM} \mathrm{NaCl}$, $1 \mathrm{mM} \beta$-ME, $0.5 \mathrm{mM}$ EDTA.

Mutant proteins and NMR samples were prepared using the same protocol described above.

\section{NMR spectroscopy}

NMR spectra were recorded at $25{ }^{\circ} \mathrm{C}$ on either a Varian 700 $\mathrm{MHz}$ or a Bruker $850 \mathrm{MHz}$ spectrometer both equipped with a cryogenic probe. The sequential backbone resonance assignments were achieved based on the following standard triple-resonance experiments: $\mathrm{HNCACB}, \mathrm{HN}(\mathrm{CO}) \mathrm{CACB}, \mathrm{HNCO}, \mathrm{HN}(\mathrm{CA}) \mathrm{CO}$ and HNCA. Non-exchangeable side chain resonance assignments were achieved using the following spectra: $\mathrm{HBHA}(\mathrm{CO}) \mathrm{NH}, \mathrm{HCC}(\mathrm{CO})$ $\mathrm{NH}, \mathrm{CC}(\mathrm{CO}) \mathrm{NH}, \mathrm{HCCH}-\mathrm{COSY}$ and HCCH-TOCSY. Approximate interproton distance restraints were derived from two $3 \mathrm{D}$ NOESY spectra: ${ }^{15} \mathrm{~N}$-edited NOESY (mixing time $100 \mathrm{~ms}$ ) and ${ }^{13} \mathrm{C}$-edited NOESY (mixing time $100 \mathrm{~ms}$ ). All of the NMR spectra were processed using NMRPipe and analyzed using NMRView or Sparky.

\section{Structural determination}

The solution structure of FAAP24 was calculated using the Xplor-NIH program, based on backbone dihedral angle restraints and NOE restraints. Backbone dihedral angle restraints ( $\varphi$ and $\psi$ angles) were obtained by the analysis of the assigned backbone chemical shift values (C, CA, CB, N and HN) using TALOS+. Interproton distance restraints were derived from the ${ }^{15} \mathrm{~N}$ - or ${ }^{13} \mathrm{C}$ edited NOESY spectra. A total of 100 structures were calculated and the final 10 structures with the lowest total energy and least experimental violations were selected to represent the FAAP24 structure. The atomic coordinates of ERCC4 domain (residues 1-139) and ( $\mathrm{HhH})_{2}$ domain (residues 155-215) have been deposited in the Protein Data Bank (PDB) with the accession codes 2M9M and $2 \mathrm{M} 9 \mathrm{~N}$, respectively. The chemical shift values of ERCC4 domain and $(\mathrm{HhH})_{2}$ domain have been deposited in the Biological Magnetic Resonance Bank (BMRB) with the accession codes 19302 and 19303, respectively.

\section{NMR titration}

The interaction between FAAP24 and ssDNA was investigated using NMR chemical shift perturbation method. Two ssDNA (one $12 \mathrm{nt}$ and one $20 \mathrm{nt}$ ) were chemically synthesized and purified with HPLC (Sangon). The lyophilized ssDNA samples were dissolved in titration buffer $\left(50 \mathrm{mM} \mathrm{K} \mathrm{HPO}_{4}-\mathrm{KH}_{2} \mathrm{PO}_{4} \mathrm{pH} 6.0,200 \mathrm{mM}\right.$ $\mathrm{NaCl}, 1 \mathrm{mM} \beta-\mathrm{ME}, 0.5 \mathrm{mM}$ EDTA) to make stock solutions of concentrations of $10 \mathrm{mM}$ before titrating into the protein samples.
Five HSQC spectra were acquired for each ssDNA ligand with a PRO/DNA ratio of 1:0, 1:0.3, 1:0.5, 1:1 and 1:2, respectively. Combined chemical shift perturbation was calculated by the formula (1),

$$
\mathrm{CSP}=\sqrt{\Delta H^{2}+\left(\frac{\Delta N}{5}\right)^{2}} \quad \text { (1), where } \Delta \mathrm{H} \text { and } \Delta \mathrm{N} \text { are the }
$$

chemical shift variations between the free and bound forms in the proton and nitrogen dimensions, respectively.

The SD of the CSP was calculated according to the following formula (2),

$$
\mathrm{SD}=\sqrt{\frac{\sum\left(C S P_{\text {res }}-C S P_{a v g}\right)^{2}}{N_{\text {res }}}}
$$

where $\mathrm{CSP}_{\text {res }}$ is the residue-specific CSP.

\section{Surface plasmon resonance (SPR) analysis}

SPR analysis was deployed using a 20 -nt substrate GCCCACCTGCAGGTTCACCC labeled with a biotin at the 5'end. The solid DNA samples were dissolved in the SPR buffer (50 mM HEPES pH 7.5 and $100 \mathrm{mM} \mathrm{NaCl}$ ). All SPR experiments were carried out at $25^{\circ} \mathrm{C}$ using a BIAcore T100 instrument (GE Healthcare). Streptavidin was immobilized to a CM5 sensor chip by the amine-coupling method. The biotin-labeled DNA was captured by streptavidin at different channels for 180 resonance units $(\mathrm{Ru})$. The binding experiments were carried out in the running buffer (50 mM HEPES pH 7.5 and $100 \mathrm{mM} \mathrm{NaCl}$ plus $0.005 \%$ $[\mathrm{v} / \mathrm{v}]$ Tween-20) at the flow rate of $30 \mu \mathrm{l} / \mathrm{min}$. Wild-type and mutant FAAP24 with different concentrations were injected over the DNA surface and blank flow cell for $60 \mathrm{~s}$ at a flow rate of $30 \mu \mathrm{l} /$ min followed by 5 min dissociation phase. Bound protein could be dissociated from the DNA completely within 1-5 min. Data were analyzed with the BIAcore T100 evaluation software by fitting to steady state affinity model.

\section{Cell culture}

Human colorectal carcinoma HCT-116 and human embryonic kidney 293T (HEK293T) cell lines were obtained from the American Type Culture Collection (ATCC). All cells were all maintained in Dulbecco's Modification of Eagles Medium (DMEM) plus $10 \%$ fetal calf serum (FBS) and grown in a humidified $5 \% \mathrm{CO}_{2^{-}}$ containing atmosphere at $37^{\circ} \mathrm{C}$.

\section{Antibodies}

FANCM and FAAP24 antibodies were described previously [34]. Sources of commercial antibodies are as follows: anti- $\beta$-actin (sc-69879, Santa Cruz); anti- $\beta$-tubulin (T4026, Sigma-Aldrich); anti-FANCD2 (sc-20022, Santa Cruz, and NB100-182, Novus); anti-histone H3 (05-928, Millipore); anti-Chk1 (sc-8408, Santa Cruz); anti-phospho-Chk1 Ser317 (2344, Cell Signaling); peroxidase-conjugated rabbit anti-mouse (315-035-048, Jackson ImmunoResearch); peroxidase-conjugated goat anti-rabbit (111-035144, Jackson ImmunoResearch); horseradish peroxidase (HRP)conjugated protein A (NA-9120V, GE Healthcare); and rhodamine Red-X-conjugated goat anti-rabbit (111-295-144, Jackson ImmunoResearch). 


\section{Western blot analysis}

Whole-cell lysates were prepared by lysing cells with NETNSDS buffer (20 mM Tris-HCl, pH 8.0, $50 \mathrm{mM} \mathrm{NaCl}, 1$ mM EDTA, $0.5 \%$ Nonidet P-40, $0.5 \%$ deoxycholate, $0.5 \%$ SDS) followed by brief sonication. Western blot analysis was performed following standard protocol. Briefly, protein samples were mixed with $2 \times$ SDS buffer, boiled, separated with SDS-PAGE, and electrotransfered onto nitrocellulose membranes, and immunoblotting was carried out with primary antibodies as indicated. After washing for three times, the membrane was incubated with secondary antirabbit or anti-mouse antibody conjugated with horseradish peroxidase. The blot was developed with enhanced chemiluminescence reagent (Amersham Biosciences).

\section{Cell fractionation}

Cells were lysed with NETN buffer $(20 \mathrm{mM}$ Tris- $\mathrm{HCl}, \mathrm{pH}$ 8.0, $100 \mathrm{mM} \mathrm{NaCl}, 1.5 \mathrm{mM} \mathrm{MgCl}, 1 \mathrm{mM}$ EDTA, $0.5 \%$ Nonidet P-40, $10 \mathrm{mM} \mathrm{NaF}, 1 \mathrm{mM} \mathrm{Na}_{3} \mathrm{VO}_{4}, 2 \mu \mathrm{g} / \mathrm{ml}$ aprotinin and $1 \mu \mathrm{g} / \mathrm{ml}$ pepstatin) at $4{ }^{\circ} \mathrm{C}$ for $30 \mathrm{~min}$ and centrifuged at $14000 \mathrm{rpm}$ for 10 $\min$. The soluble fraction contains the cytosol and soluble nuclear proteins. The insoluble chromatin enriched pellet was washed with phosphate buffered saline (PBS) for three times and extracted with $0.2 \mathrm{~N} \mathrm{HCl}$ for $30 \mathrm{~min}$ on ice, and the extract was neutralized with equal volume of $1 \mathrm{M}$ Tris- $\mathrm{HCl}(\mathrm{pH} 8.0)$.

\section{Immunofluorescence staining}

Cells were cultured on cover slips and treated with desired dosage of MMC for $24 \mathrm{~h}$. Cells were then washed with PBS, fixed with $3 \%$ formaldehyde for $15 \mathrm{~min}$ and permeabilized with $0.5 \%$ Triton buffer (20 mM HEPES, pH7.4, $50 \mathrm{mM} \mathrm{NaCl}, 3 \mathrm{mM} \mathrm{MgCl}$, $300 \mathrm{mM}$ sucrose, $0.5 \%$ Triton X-100) for $5 \mathrm{~min}$ at room temperature. Samples were incubated sequentially with desired primary and secondary antibodies for $30 \mathrm{~min}$, and finally stained with 4', 6-diamidino-2-phenylindole (DAPI) for $2 \mathrm{~min}$ in dark, all at room temperature. Cover slips were mounted on slides with 1, 4-phenylenediamine based anti-fade solution, and visualized under Nikon Eclipse 90i fluorescence microscopy. Nuclear foci were counted in at least 100 nuclei at 5 different locations for each sample.

\section{Clonogenic survival assay}

Cells were seeded at a density of $1-3 \times 10^{5}$ cells per $100 \mathrm{~mm}$ culture plate and allowed to attach and recover overnight. Cells were then exposed to MMC at dosages ranging from $100 \mathrm{nM}$ to $5000 \mathrm{nM}$ for $1 \mathrm{~h}$. After MMC treatment, cells were seeded at appropriate densities in triplicates for each dosage group, and grown in MMC-free medium for approximately 14 days. Cell colonies were then fixed with $6 \%$ glutaraldehyde $(\mathrm{v} / \mathrm{v})$ and stained with $0.5 \%$ crystal violet $(\mathrm{w} / \mathrm{v})$. Colonies containing more than 50 cells were counted, and relative survival was calculated as follows: \% survival $=$ no. of colonies counted $/($ no. of cells plated $\times$ plating efficiency) $\times 100$.

\section{Acknowledgments}

We thank members of the laboratories for helpful discussions and technical assistances. This work was supported by grants from the National Basic Research Program of China (973 Program: 2011CB910503 and 2012CB917202), the National Natural Science Foundation of China (31021062 and 31100538), and the
National Cancer Institute (CA127945 and CA097175 Project 3 to LL).

\section{References}

1 Ciccia A, McDonald N, West SC. Structural and functional relationships of the XPF/MUS81 family of proteins. Annu Rev Biochem 2008; 77:259-287.

2 Bergstralh DT, Sekelsky J. Interstrand crosslink repair: can XPF-ERCC1 be let off the hook? Trends Genet 2008; 24:7076.

3 Kelsall IR, Langenick J, MacKay C, Patel KJ, Alpi AF. The Fanconi anaemia components UBE2T and FANCM are functionally linked to nucleotide excision repair. PLoS One 2012; 7:e36970.

4 Meetei AR, Medhurst AL, Ling C, et al. A human ortholog of archaeal DNA repair protein Hef is defective in Fanconi anemia complementation group M. Nat Genet 2005; 37:958-963.

5 Crossan GP, Patel KJ. The Fanconi anaemia pathway orchestrates incisions at sites of crosslinked DNA. J Pathol 2012; 226:326-337.

6 Moldovan GL, D'Andrea AD. How the Fanconi anemia pathway guards the genome. Annu Rev Genet 2009; 43:223-249.

7 D'Andrea AD. Susceptibility pathways in Fanconi's anemia and breast cancer. The N Engl J Med 2010; 362:1909-1919.

8 Ling C, Ishiai M, Ali AM, et al. FAAP100 is essential for activation of the Fanconi anemia-associated DNA damage response pathway. Embo J 2007; 26:2104-2114.

9 Ciccia A, Ling C, Coulthard R, et al. Identification of FAAP24, a Fanconi anemia core complex protein that interacts with FANCM. Mol Cell 2007; 25:331-343.

10 Ali AM, Pradhan A, Singh TR, et al. FAAP20: a novel ubiquitin-binding FA nuclear core-complex protein required for functional integrity of the FA-BRCA DNA repair pathway. Blood 2012; 119:3285-3294.

11 Kim H, Yang K, Dejsuphong D, D'Andrea AD. Regulation of Rev1 by the Fanconi anemia core complex. Nat Struct Mol Biol 2012; 19:164-170.

12 Leung JW, Wang Y, Fong KW, Huen MS, Li L, Chen J. Fanconi anemia (FA) binding protein FAAP20 stabilizes FA complementation group A (FANCA) and participates in interstrand cross-link repair. Proc Natl Acad Sci USA 2012; 109:4491-4496.

13 Yan Z, Guo R, Paramasivam M, et al. A ubiquitin-binding protein, FAAP20, links RNF8-mediated ubiquitination to the Fanconi anemia DNA repair network. Mol Cell 2012; 47:6175 .

14 Singh TR, Saro D, Ali AM, et al. MHF1-MHF2, a histonefold-containing protein complex, participates in the Fanconi anemia pathway via FANCM. Mol Cell 2010; 37:879-886.

15 Yan Z, Delannoy M, Ling C, et al. A histone-fold complex and FANCM form a conserved DNA-remodeling complex to maintain genome stability. Mol Cell 2010; 37:865-878.

16 Smogorzewska A, Matsuoka S, Vinciguerra P, et al. Identification of the FANCI protein, a monoubiquitinated FANCD2 paralog required for DNA repair. Cell 2007; 129:289-301.

17 Wang W. Emergence of a DNA-damage response network consisting of Fanconi anaemia and BRCA proteins. Nat Rev Genet 2007; 8:735-748. 
18 Meetei AR, Yan Z, Wang W. FANCL replaces BRCA1 as the likely ubiquitin ligase responsible for FANCD2 monoubiquitination. Cell Cycle 2004; 3:179-181.

19 Kratz K, Schopf B, Kaden S, et al. Deficiency of FANCD2associated nuclease KIAA1018/FAN1 sensitizes cells to interstrand crosslinking agents. Cell 2010; 142:77-88.

20 Liu T, Ghosal G, Yuan J, Chen J, Huang J. FAN1 acts with FANCI-FANCD2 to promote DNA interstrand cross-link repair. Science 2010; 329:693-696.

21 Smogorzewska A, Desetty R, Saito TT, et al. A genetic screen identifies FAN1, a Fanconi anemia-associated nuclease necessary for DNA interstrand crosslink repair. Mol Cell 2010; 39:36-47.

22 MacKay C, Declais AC, Lundin C, et al. Identification of KIAA1018/FAN1, a DNA repair nuclease recruited to DNA damage by monoubiquitinated FANCD2. Cell 2010; 142:6576.

23 Crossan GP, van der Weyden L, Rosado IV, et al. Disruption of mouse Slx4, a regulator of structure-specific nucleases, phenocopies Fanconi anemia. Nat Genet 2011; 43:147-152.

24 Stoepker C, Hain K, Schuster B, et al. SLX4, a coordinator of structure-specific endonucleases, is mutated in a new Fanconi anemia subtype. Nat Genet 2011; 43:138-141.

25 Reid S, Schindler D, Hanenberg H, et al. Biallelic mutations in PALB2 cause Fanconi anemia subtype FA-N and predispose to childhood cancer. Nat Genet 2007; 39:162-164.

26 Howlett NG, Taniguchi T, Olson S, et al. Biallelic inactivation of BRCA2 in Fanconi anemia. Science 2002; 297:606-609.

27 Levitus M, Waisfisz Q, Godthelp BC, et al. The DNA helicase BRIP1 is defective in Fanconi anemia complementation group J. Nat Genet 2005; 37:934-935.

28 Xia B, Dorsman JC, Ameziane N, et al. Fanconi anemia is associated with a defect in the BRCA2 partner PALB2. Nat Genet 2007; 39:159-161.

29 Vaz F, Hanenberg H, Schuster B, et al. Mutation of the $R A D 51 C$ gene in a Fanconi anemia-like disorder. Nat Genet 2010; 42:406-409.

30 Hoadley KA, Xue Y, Ling C, Takata M, Wang W, Keck JL. Defining the molecular interface that connects the Fanconi anemia protein FANCM to the Bloom syndrome dissolvasome. Proc Natl Acad Sci USA 2012; 109:4437-4442.

31 Gari K, Decaillet C, Stasiak AZ, Stasiak A, Constantinou A. The Fanconi anemia protein FANCM can promote branch mi- gration of Holliday junctions and replication forks. Mol Cell 2008; 29:141-148.

32 Gari K, Decaillet C, Delannoy M, Wu L, Constantinou A. Remodeling of DNA replication structures by the branch point translocase FANCM. Proc Natl Acad Sci USA 2008; 105:16107-16112.

33 Kim JM, Kee Y, Gurtan A, D'Andrea AD. Cell cycle-dependent chromatin loading of the Fanconi anemia core complex by FANCM/FAAP24. Blood 2008; 111:5215-5222.

34 Wang Y, Leung JW, Jiang Y, et al. FANCM and FAAP24 maintain genome stability via cooperative as well as unique functions. Mol Cell 2013; 49:997-1009.

35 Collis SJ, Ciccia A, Deans AJ, et al. FANCM and FAAP24 function in ATR-mediated checkpoint signaling independently of the Fanconi anemia core complex. Mol Cell 2008; 32:313324.

36 Huang M, Kim JM, Shiotani B, Yang K, Zou L, D’Andrea $\mathrm{AD}$. The FANCM/FAAP24 complex is required for the DNA interstrand crosslink-induced checkpoint response. Mol Cell 2010; 39:259-268.

37 Schwab RA, Blackford AN, Niedzwiedz W. ATR activation and replication fork restart are defective in FANCM-deficient cells. EMBO J 2010; 29:806-818.

38 Enzlin JH, Scharer OD. The active site of the DNA repair endonuclease XPF-ERCC1 forms a highly conserved nuclease motif. EMBO J 2002; 21:2045-2053.

39 Wienk H, Slootweg JC, Speerstra S, Kaptein R, Boelens R, Folkers GE. The Fanconi anemia associated protein FAAP24 uses two substrate specific binding surfaces for DNA recognition. Nucleic Acids Res 2013; 41:6739-6749.

40 Shao X, Grishin NV. Common fold in helix-hairpin-helix proteins. Nucleic Acids Res 2000; 28:2643-2650.

41 Tripsianes K, Folkers GE, Zheng C, et al. Analysis of the XPA and ssDNA-binding surfaces on the central domain of human ERCC1 reveals evidence for subfunctionalization. Nucleic Acids Res 2007; 35:5789-5798.

42 Newman M, Murray-Rust J, Lally J, et al. Structure of an XPF endonuclease with and without DNA suggests a model for substrate recognition. EMBO J 2005; 24:895-905.

43 Tripsianes K, Folkers G, Ab E, et al. The structure of the human ERCC1/XPF interaction domains reveals a complementary role for the two proteins in nucleotide excision repair. Structure 2005; 13:1849-1858.

(Supplementary information is linked to the online version of the paper on the Cell Research website.) 